\title{
Crystal-field model study of the xenon hexafluoride molecule. II. Comparisons with other hexavalent xenon molecules
}

\author{
Sylvester Y. Wang and Lawrence L. Lohr, Jr. \\ Department of Chemistry, University of Michigan, Ann Arbor, Michigan 48104 \\ (Received 25 June 1973)
}

\begin{abstract}
The two-electron crystal-field model previously used to describe in detail the energy levels of $\mathrm{XeF}_{6}$ is applied to other hexavalent xenon systems, namely the $\mathrm{XeOF}_{4}, \mathrm{XeO}_{2} \mathrm{~F}_{2}$, and $\mathrm{XeO}_{3}$ molecules and the $\mathrm{XeF}_{8}^{2-}$ ion. Comparisons of the calculated excited state energies of these three molecules at their observed geometries are made to those calculated for various geometries of $\mathrm{XeF}_{6}$. The strong low symmetry fields in $\mathrm{XeOF}_{4}, \mathrm{XeO}_{2} \mathrm{~F}_{2}$, and $\mathrm{XeO}_{3}$ result in very high excitation energies, which may also be taken to represent greater energy stabilization for the lone electron pair relative to that for $\mathrm{XeF}_{6}$. The ground state energy of $\mathrm{XeF}_{8}^{2-}$ is explored as a function of geometry, and within the two-space considered, the results match the structure observed in solid $(\mathrm{NO})_{2} \mathrm{XeF}_{8}$.
\end{abstract}

\section{INTRODUCTION}

In a recent publication ${ }^{1}$ we have outlined in detail a two-electron crystal-field model of the electronic structure of the $\mathrm{XeF}_{6}$ molecule and presented results for the ground and excited state energies as a function of molecular geometry and of several energy parameters. It is the purpose of this paper to put the $\mathrm{XeF}_{6}$ results into chemical perspective by comparisons with the results of similar calculations on other Xe (VI) systems, each described in terms of the wavefunctions for the highest energy electron pair in an effective "crystal field" generated by the nuclei and the rest of the electrons in the molecule. The computational details ${ }^{1}$ are not repeated here, except to point out that the energies and wavefunctions are obtained by the diagonalization of a $28 \times 28$ matrix representing crystal-field, electron-repulsion, and spin-orbit interactions within the basis of the 28 two-electron states constructed from xenon $5 s$ and $5 p$ orbitals. Ligand-ligand interactions are also included via point-charge repulsions and make an important contribution to the shapes of potential energy curves. The necessary parameters ${ }^{1}$ are the effective one-electron energy gap $\Delta E_{5 s-5 p}$, the electron-repulsion integrals $F_{1}(5 s, 5 p)$ and $F_{2}(5 p, 5 p)$, the one-electron spin-orbit parameter $\zeta_{5 p}$, and the radial integrals $\left\langle r^{2}\right\rangle_{p p}^{1 / 2}$ and $\left\langle r_{s p}\right.$. The four energy parameters are taken in this study to be the same as those used in most of the $\mathrm{XeF}_{6}$ calculations, and are given in Sec. II. The radial integral $\left\langle r^{2}\right\rangle_{p p}^{1 / 2}$ is the root-mean-square electron radius for the $5 p$ orbital, while $\langle r\rangle_{s p}$ is the radial matrix element of scalar $r$ between $5 s$ and $5 p$. The values of these parameters are the same as those used before, namely 1.64954 and 2.05495 a. u., respectively.

\section{THE $\mathrm{XeOF}_{4}, \mathrm{XeO}_{2} \mathrm{~F}_{2}$, AND $\mathrm{XeO}_{3} \mathrm{MOLECULES}$}

In this section we present results of crystal-field calculations of the type previously described, but here applied to molecules other than $\mathrm{XeF}_{6}$. The energy parameters were kept at the values $\Delta E_{5 s-5 p}=3.5 \mathrm{eV}, F_{1}$ $=0.5 \mathrm{eV}, F_{2}=0.08 \mathrm{eV}$, and $\zeta_{5 p}=0.87 \mathrm{eV}$, these values corresponding to the so-called "best" set of those used in the $\mathrm{XeF}_{6}$ study. ${ }^{1}$ For each of the molecules $\mathrm{XeOF}_{4}$, $\mathrm{XeO}_{2} \mathrm{~F}_{2}$, and $\mathrm{XeO}_{3}$, only a single geometry was considered, with that being a reported equilibrium geometry. Charges of -2 for oxygen and -1 for fluorine were used in the crystal-field analysis. The microwave structure $^{2}$ of $\mathrm{XeOF}_{4}$ is characterized by $C_{4 v}$ symmetry and bond lengths of $1.70 \pm 0.05 \AA$ for $\mathrm{Xe}-\mathrm{O}$ and 1.95 $\pm 0.05 \AA$ for $\mathrm{Xe}-\mathrm{F}$, with an $\angle \mathrm{O}-\mathrm{Xe}-\mathrm{F}$ of $91^{\circ} \pm 2^{\circ}$. The structural parameters we used were $1.71 \AA$ for Xe-O and $1.90 \AA$ for $\mathrm{Xe}-\mathrm{F}$ (this latter value chosen to be essentially the same as that for $\mathrm{XeF}_{6}$ ), with an $\angle \mathrm{O}-\mathrm{Xe}-\mathrm{F}$ of $90^{\circ}$, implying that the four fluorines are coplanar with the xenon atom. These bond lengths are in fact the refined microwave values as quoted ${ }^{3}$ by Begun, Fletcher, and Smith, based on a private communication from Martins and Wilson. For $\mathrm{XeO}_{2} \mathrm{~F}_{2}$ we assumed a $C_{2 v}$ structure, as indicated ${ }^{4}$ by its vibrational spectra, with assumed parameters of $1.90 \AA$ for $\mathrm{Xe}-\mathrm{F}, 1.70 \AA$ for $\mathrm{Xe}-\mathrm{O}, \angle \mathrm{O}-\mathrm{Xe}-\mathrm{O}=100^{\circ}$ and $\angle \mathrm{O}-\mathrm{Xe}-\mathrm{F}=90^{\circ}$, thus making the structure much like that determined ${ }^{5}$ by $\mathrm{x}$ rays for the isoelectronic $\mathrm{IO}_{2} \mathrm{~F}_{2}^{-}$ion in the solid $\mathrm{KIO}_{2} \mathrm{~F}_{2}$. Finally the $C_{3 v}$ structure for $\mathrm{XeO}_{3}$ is taken to be that determined ${ }^{6}$ by $\mathrm{x}$ rays for the solid, with $1.76 \AA$ for $\mathrm{Xe}-\mathrm{O}$ and $\angle \mathrm{O}-\mathrm{Xe}-\mathrm{O}=103^{\circ}$.

The crystal-field results for the $\mathrm{XeOF}_{4}$ and $\mathrm{XeO}_{3}$ molecules are shown in Fig. 1, together with those for three different structures of $\mathrm{XeF}_{6}$, namely octahedral, $C_{3 v}$ (at radial minimum ${ }^{1}$ in pure $t_{1 u}$ bending space), and $C_{3 v}$ (at minimum ${ }^{1}$ in $t_{1 u}-t_{2 g}$ bending space). For comparative purposes the energy of the lowest two-electron state $\left[{ }^{1} S_{0}\right.$ of free $\mathrm{Xe}(+6)$ ion] is assigned a value of zero for each species, with the shaded regions grouping together all levels associated with the same orbital configuration. Structure within each shaded region is indicated by horizontal lines and results from exchange splittings and spin-orbit coupling. Thus, for $\mathrm{XeF}_{6}\left(O_{h}\right)$, there are three groupings corresponding to the configurations $5 s^{2}, 5 s 5 p$, and $5 p^{2}$, while for $\mathrm{XeOF}_{4}$ and $\mathrm{XeO}_{3}$, with strong axial fields, there are six groupings. For the distorted $\mathrm{XeF}_{6}$ structures some of these groupings are incompletely separated, so that four are shown. The ground-state stabilization of $\mathrm{XeF}_{6}$ accompanying $t_{1 u}$ deformations is reflected in Fig. 1 as an increase in the excitation energies relative to those of the $O_{n}$ structure. The excited states are even higher in energy for $\mathrm{XeOF}_{4}$ and $\mathrm{XeO}_{3}$, where the large axial fields not only mix $5 s$ and $5 p$ orbitals to a considerable degree but also split the $5 p$ orbitals by a very large first-order effect from the $l=2$ part of the field. Indeed the first absorp- 
TABLE I. Comparison of energy levels, ${ }^{a, b}$.

\begin{tabular}{|c|c|c|c|c|}
\hline Level & $\left|M_{J}\right|$ & $\mathrm{XeF}_{6}\left(O_{h}\right)$ & $\mathrm{XeOF}_{4}$ & $\mathrm{XeO}_{3}$ \\
\hline${ }^{1} S_{0}$ & 0 & 0.0 & 0.0 & 0.0 \\
\hline${ }^{3} P_{0}^{0}$ & 0 & 2.48 & 7.24 & 7.19 \\
\hline \multirow{2}{*}{${ }^{3} P_{1}^{0}$} & 0 & 2.68 & 7.22 & 7.18 \\
\hline & 1 & 2.68 & 7.65 & 7.60 \\
\hline \multirow[t]{3}{*}{${ }^{3} P_{2}^{0}$} & 0 & 3.78 & 11.88 & 14.86 \\
\hline & 1 & 3.78 & 11.90 & 14.85 \\
\hline & 2 & 3.78 & 8.14 & 8.08 \\
\hline \multirow[t]{2}{*}{${ }^{1} P_{1}^{0}$} & 0 & 4.58 & 11.87 & 14.83 \\
\hline & 1 & 4.58 & 8.48 & 8.46 \\
\hline${ }^{3} P_{0}$ & 0 & 5.44 & 15.73 & 15.65 \\
\hline \multirow[t]{2}{*}{${ }^{3} \boldsymbol{P}_{1}$} & 0 & 6.42 & 20.16 & 22.91 \\
\hline & 1 & 6.42 & 16.28 & 16.15 \\
\hline \multirow[t]{3}{*}{${ }^{3} P_{2}^{!}$} & 0 & 6.70 & 17.78 & 17.65 \\
\hline & 1 & 6.70 & 20.47 & 23.34 \\
\hline & 2 & 6.70 & 16.75 & 23.80 \\
\hline \multirow[t]{3}{*}{${ }^{1} D_{2}$} & 0 & 7.93 & 20.03 & 23.01 \\
\hline & 1 & 7.93 & 21.20 & 24.07 \\
\hline & 2 & 7.93 & 20.94 & 16.63 \\
\hline${ }^{1} S_{0}$ & 0 & 8.70 & 25.66 & 31.55 \\
\hline
\end{tabular}

All energies are in electron volts and relative to that for the lowest level for each species. The energy parameters are $\Delta E_{5 s-5 p}=3.5 \mathrm{eV}, F_{1}=0.5 \mathrm{eV}, F_{2}=0.08 \mathrm{eV}$, and $\zeta_{5 p}=0.87 \mathrm{eV}$. bolecular levels are designated by the principal free-ion level, as ascertained by inspection of the eigenvectors in a free-ion basis. For XeOF ${ }_{4}\left(C_{4 v}\right)$ and $\mathrm{XeO}_{3}\left(C_{3 v}\right)$, only $M_{J}$ is a "good" quantum number; specifically $L, S, J$, and the parity are not.

tion bands for $\mathrm{XeOF}_{4}$ and $\mathrm{XeO}_{3}$ are predicted to occur at almost twice the energy of those for $\mathrm{XeF}_{6}\left(C_{3 v}\right.$, combined $t_{1 u}$ and $t_{2 g}$ distortions), with both spin singlet and triplet states contained within the shaded region for the $5 s 5 p_{x}$ and $5 s 5 p_{y}$ configurations (the molecular symmetry axis is taken to be $z$ ). The energies are given in detail in Table I, where the levels are designated by the principal free-ion $\mathrm{Xe}(+6)$ level. All levels with $\left|M_{J}\right|>0$ are doubly denerate, with $M_{\boldsymbol{J}}$ being the only "good" quantum number for the axially symmetric molecules. The liquid state of $\mathrm{XeOF}_{4}$ is described ${ }^{7}$ as colorless, with a refractive index $n_{D}=1.4215$ at $25^{\circ} \mathrm{C}$, while $\mathrm{XeO}_{3}$ is a white solid. The low value of $n_{D}$ certainly argues against the presence of low-lying electronic states for $\mathrm{XeOF}_{4}$. An interesting feature in Fig. 1 is that the energy difference between the $5 s$ and the $5 p_{x}$ or $5 p_{y}$ orbitals is virtually the same for $\mathrm{XeOF}_{4}$ and $\mathrm{XeO}_{3}$, while the $5 s-5 p_{z}$ difference is significantly greater (about $25 \%$ ) in $\mathrm{XeO}_{3}$.

Although similar results were obtained for $\mathrm{XeO}_{2} \mathrm{~F}_{2}$ $\left(C_{2 v}\right)$, these are not presented in detail here. The low symmetry causes the degeneracy of the spin-orbit levels to be completely lifted, while the levels themselves are not as well separated according to the various two-electron configurations. In general the $\mathrm{XeO}_{2} \mathrm{~F}_{2}$. excitation energies are roughly $10 \%$ higher than the corresponding ones for $\mathrm{XeO}_{3}$. Specifically the lowest triplet component is calculated to occur at $8.1 \mathrm{eV}$ in
$\mathrm{XeO}_{2} \mathrm{~F}_{2}$, as compared to $7.2 \mathrm{eV}$ in $\mathrm{XeO}_{3}$ and $\mathrm{XeOF}_{4}, 4.2$ $\mathrm{eV}$ in $\mathrm{XeF}_{6}\left(C_{3 v}, t_{1 u}\right.$, and $\left.t_{2 s}\right), 3.2 \mathrm{eV}$ in $\mathrm{XeF}_{6}\left(C_{3 v}, t_{1 u}\right.$ only), and $2.5 \mathrm{eV}$ in $\mathrm{XeF}_{6}\left(O_{h}\right) . \mathrm{XeO}_{2} \mathrm{~F}_{2}$, like $\mathrm{XeO}_{3}$, is a white solid, so that the results appear consistent, at least, even though an excitation energy of $65000 \mathrm{~cm}^{-1}$ seems excessive.

It is interesting to compare these results with those from a recent ${ }^{8}$ Wolfsberg-Helmholz (extended Hückel) treatment of $\mathrm{XeOF}_{4}, \mathrm{XeO}_{2} \mathrm{~F}_{2}$, and the T-shaped tetravalent species $\mathrm{XeOF}_{2}$. These studies employed an $\mathrm{F}(2 \mathrm{~s}$ and $2 p$ ) and $\mathrm{Xe}(5 s$ and $5 p)$ basis in the semiempirical construction of molecular orbitals. For $\mathrm{XeOF}_{4}$ the highest occupied MO is of $a_{1}$ symmetry in group $C_{4 v}$ and is a strongly admixed orbital containing $\mathrm{Xe}(5 s), \mathrm{Xe}(5 p)$, and $F(2 p \sigma)$ orbitals. Its energy is $9.85 \mathrm{eV}$ below the unoccupied (virtual) $e$ orbital consisting largely of $\mathrm{Xe}(5 p)$, and $20.38 \mathrm{eV}$ below the unoccupied and strongly antibonding $a_{1}$ orbital, the latter containing some $\mathrm{O}(2 p \sigma)$ character. For $\mathrm{XeO}_{2} \mathrm{~F}_{2}\left(C_{2 v}\right)$ the gap between the highest occupied $\left(a_{1}\right)$ orbital and the lowest unoccupied $\left(b_{1}\right)$ orbital is $14.39 \mathrm{eV}$, much larger than for $\mathrm{XeOF}_{4}$, a result qualitatively identical to our crystal-field conclusion concerning higher exictation energies in $\mathrm{XeO}_{2} \mathrm{~F}_{2}$ than in $\mathrm{XeOF}_{4}$. The $\mathrm{Xe}$ (IV) species $\mathrm{XeOF}_{2}$ corresponds to a four-electron system in our method, and could be treated as such, although we have not done so. Here the gap between the highest occupied $\left(a_{1}\right)$ and the lowest unoccupied $\left(b_{2}\right)$ orbital is $15.28 \mathrm{eV}$, larger than for $\mathrm{XeOF}_{4}$. Interestingly the extra lone pair [relative to $\mathrm{Xe}(\mathrm{VI})$ sys-

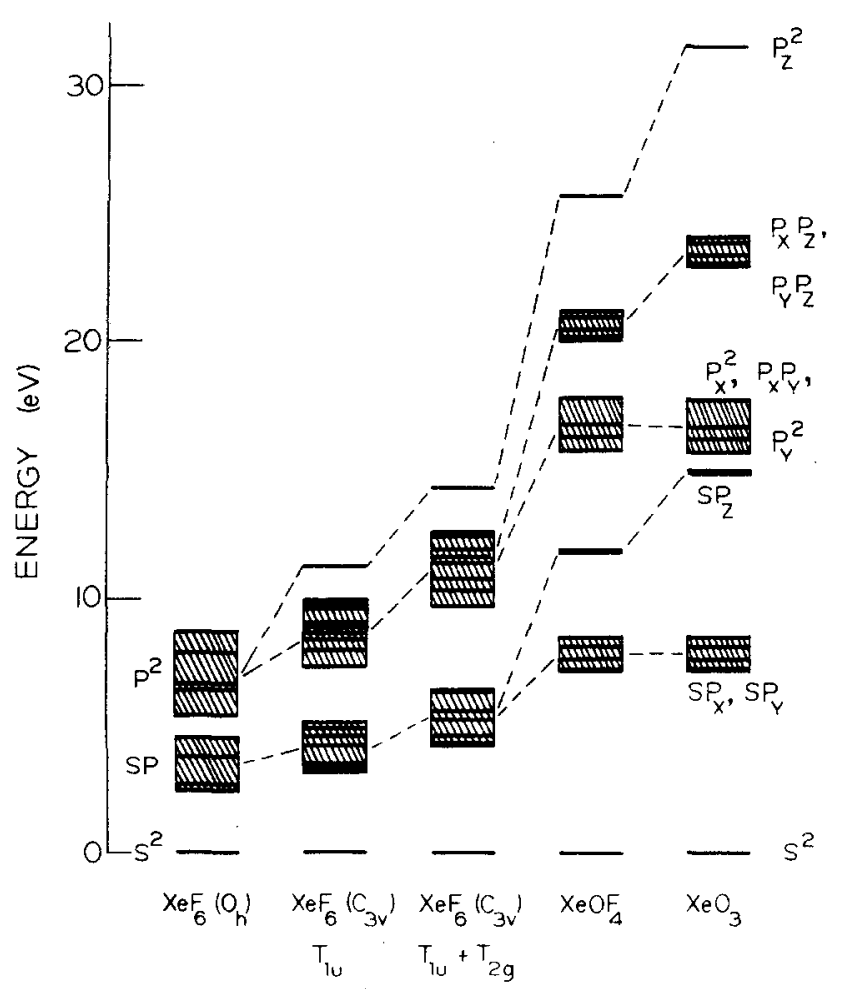

FIG. 1. Energy levels in electron volts for $\mathrm{XeOF}_{4}\left(C_{4 v}\right)$ and $\mathrm{XeO}_{3}\left(\boldsymbol{C}_{3 v}\right)$ compared to those for three different structures of $\mathrm{XeF}_{6}$ (see Ref. 1). Electronic parameters are $\Delta E_{5 s-5 p}=3.5 \mathrm{eV}$, $F_{1}=0.5 \mathrm{eV}, F_{2}=0.08 \mathrm{eV}$, and $\zeta_{5 p}=0.87 \mathrm{eV}$. Horizontal lines denote each energy, but the double degeneracy of some levels is not indicated. Shaded areas enclose all levels of a given twoelectron configuration. See Table I for detailed values. 
tems] is in a $b_{1}$ orbital with an energy $1.3 \mathrm{eV}$ below that of the $\alpha_{1}$ orbital. The number and arrangement of the ligands permits a low energy for an extra pair, as it does for square-planar $\mathrm{XeF}_{4}$.

For all species considered in this section, the high electronic excitation energies as compared to those computed for $\mathrm{XeF}_{6}, O_{h}$ or $C_{3 v}$, can be taken to reflect an enhanced energy stabilization of the two-electron ground state, which is of ten referred to as the "lone pair." The semiempirical molecular orbital results ${ }^{8}$ can be given a similar interpretation, with the strong low-symmetry fields producing greater $5 s-5 p$ mixing than even in distorted $\mathrm{XeF}_{6}$.

\section{III. $\mathrm{XeF}_{8}^{2-} \mathrm{ION}$}

A species closely related to $\mathrm{XeF}_{6}$ is the $\mathrm{XeF}_{8}{ }^{2-}$ anion, such as present in the crystalline solid (NO) ${ }_{2} \mathrm{XeF}_{8}$, nitrosonium octafluoroxenate (VI). The x-ray studies ${ }^{9}$ of this material reveal a slightly distorted Archimedian antiprismatic structure for $\mathrm{XeF}_{8}^{2-}$. Although only a mirror plane symmetry for the ion is required by the orthorhombric space group Pnma, the structure is close to the $D_{4 d}$ symmetry of an antiprism. The five different $\mathrm{Xe}-\mathrm{F}$ bond lengths are found to be 1.946(5), 1.958(7), 1.971(7), 2.052(5), and 2.099(5) $\AA$. The average polar angle for the ligands $w$ ith respect to the approximate $S_{8}$ axis is $57.9^{\circ}$ (or $180^{\circ}-57.9^{\circ}=122.1^{\circ}$ ).

We have carried out crystal-field calculations similar to those for the other $\mathrm{Xe}(+6)$ systems, using the same energy parameters and an $\mathrm{Xe}-\mathrm{F}$ distance of $2.0 \AA$, close to the observed average. Specifically we have explored the variation of the ground-state energy, including ligand-ligand repulsions, as a function of the two angles necessary for describing a complex of assumed $D_{4}$ symmetry. These angles are a polar angle $\theta$ and an azimuthai angle $\phi$, where $\phi=0,90^{\circ}, 180^{\circ}$, or $270^{\circ}$ for $D_{4 h}$ structures, and $\phi=45^{\circ}, 135^{\circ}, 225^{\circ}$, or $315^{\circ}$ for $D_{4 d}$ structures. The resulting potential energy contours are shown in Fig. 2. The minimum energy occurs for a $D_{4 d}$ structure $\left(\phi=45^{\circ}\right)$ with $\theta=57^{\circ}$, essentially identical to the observed average of $57.9^{\circ}$ (the observed angle ranges from $56.1^{\circ}$ to $58.7^{\circ}$ for various fluorines in the $C_{s}$ complex). This $D_{4 d}$ structure is flattened with respect to a "rotated" cube for which $\theta=\cos ^{-1}\left(3^{-1 / 2}\right)$ $=54.74^{\circ}$, but not so flattened as a $D_{4 d}$ polyhedron with two square and eight equilateral triangular faces for which $\theta=\tan ^{-1}\left(8^{-1 / 4}\right)=59.26^{\circ}$ (the true antiprism). The energy at the $D_{4 d}$ minimum in the two space of $\mathrm{Fig} .2$ is $0.54 \mathrm{eV}$ below that for a cubal $O_{h}$ structure. Our results are largely due to ligand repulsions, as there is no $5 s-5 p$ mixing for the general symmetry $D_{4}$ of this surface. A consequence of this is the further result that energy differences between ground and excited states are, in our model, essentially the same, except for small splittings due to the $l=2$ part of the crystal field, as those for $\mathrm{XeF}_{6}\left(O_{h}\right)$. It should be pointed out that we have not considered geometries for $\mathrm{XeF}_{8}^{2-}$ which would permit significant $5 s-5 p$ mixing and thus provide a ninth coordination position for the lone pair. Throughout our surface (Fig. 2), the lone pair remains in a spherical $5 s^{2}$ distribution (there is of course some mixing with the
${ }^{1} S_{0}$ and ${ }^{3} P_{0}$ levels of $\left.5 p^{2}\right)$. It should also be noted that a cubal $\left(O_{h}\right)$ structure for $\mathrm{XeF}_{8}^{2-}$ corresponds to a saddle point in Fig. 2, this structure being at a minimum with respect to the angle $\theta$, but a maximum with respect to the angle $\phi$.

There are other $\mathrm{Xe}$ (VI) systems which we have not considered as very little is known about them at this time. These include the ion $\mathrm{XeF}_{5}^{+}$, present ${ }^{10}$ in $\mathrm{XeF}_{6} \mathrm{BF}_{3}$ and possibly ${ }^{11,12}$ in other adducts, such as those with $\mathrm{SbF}_{5}, \mathrm{SnF}_{4}, \mathrm{GeF}_{4}$, etc.; the ion $\mathrm{XeF}_{7}^{-}$which may be present ${ }^{13}$ in the solids $\mathrm{CsXeF}_{7}$ and $\mathrm{RbXeF}_{7}$; and the ion $\mathrm{XeO}_{4}^{-2}$, present $t^{14}$ in the solid xenate $\mathrm{CsHXeO}_{4}$. With respect to the latter species, our model would yield for an $\mathrm{XeO}_{4}^{2-}$ species with assumed tetrahedral symmetry identical energy levels to those for $\mathrm{XeF}_{6}\left(O_{h}\right)$, provided that identical energy parameters were used in the two cases. These parameters differ, of course, rather considerably from those for an isolated $\mathrm{Xe}(+6)$ ion due to nephelauxetic and related effects, and perhaps should be significantly lower for $\mathrm{XeO}_{4}^{2-}$ as compared to $\mathrm{XeF}_{6}$. The pseudo-Jahn-Teller active modes for $\mathrm{XeO}_{4}^{2-}$ would, of course, be the $t_{2}$ bending and stretching modes, which would mix $5 s$ and $5 p$ xenon orbitals.

There remains the important problem of the ultraviolet absorption spectrum of gaseous $\mathrm{XeF}_{6}$. A significant feature of the reported ${ }^{15}$ spectrum is the long "tail" of the first absorption band at approximately $3400 \AA$ $\left(29400 \mathrm{~cm}^{-1}\right)$, with this tail not only extending well into the visible (to about $4500 \AA$ ), but also showing a marked

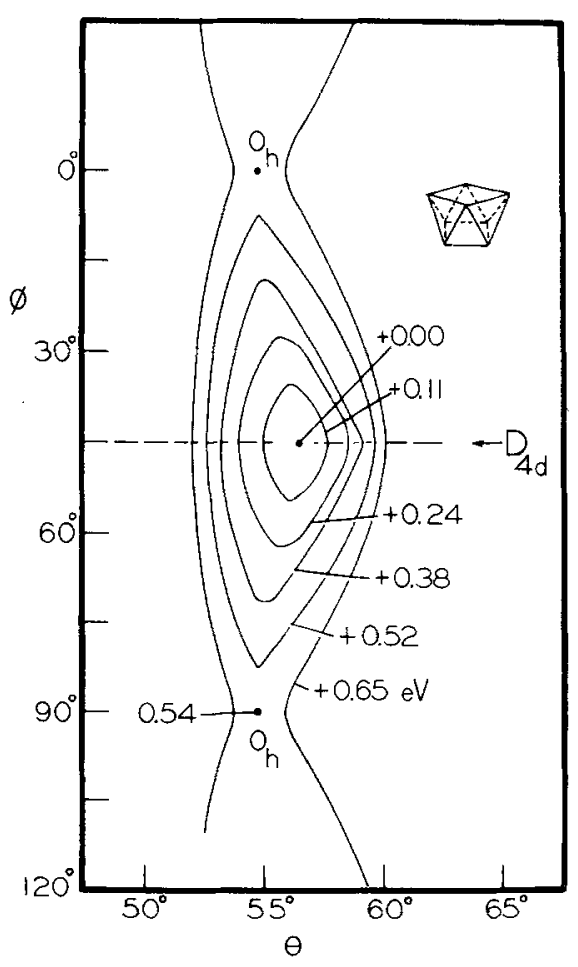

FIG. 2. Potential energy contours in electron volts for the ground state of $\mathrm{XeF}_{8}^{2-}$ with $\mathrm{Xe}-\mathrm{F}=2.0 \AA$ and electronic parameters $\Delta E_{5 s-5 p}=3.5 \mathrm{eV}, F_{1}=0.5 \mathrm{eV}, F_{2}=0.08 \mathrm{eV}$, and $\zeta_{5 p}=0.87$ eV. The molecular symmetry is at least $D_{4}$ at all points on this surface, with cubal $O_{h}$ structures occuring when the aximuthal angle $\phi$ is $0^{\circ}$ or $90^{\circ}$ and the polar angle $\theta=54.74^{\circ}$. Struc. tures with $\phi=45^{\circ}$ have $D_{4 d}$ symmetry. 
increase in absorbance upon increasing the sample temperature from 25 to $90^{\circ} \mathrm{C}$. By contrast the absorbance decreases with increasing temperature in the spectral range 3000-3300 $\AA$. These and other spectral features were interpreted ${ }^{16}$ within the framework of an electronic isomers model, in which the $\mathrm{XeF}_{6}$ vapor is described as an equilibrium mixture of octahedral spin-singlet ground-state molecules and trigonally distorted (both prolate and oblate), spin-triplet excited state molecules. Part III of this series will present the spectral energies, intensities, and band shapes as obtained from our two-electron crystal-field model.

${ }^{1}$ S. W. Wang and L. L. Lohr, Jr., J. Chem. Phys. 60, 3901 (1974), the preceding article.

${ }^{2}$ J. Martins and E. B. Wilson, J. Chem. Phys. 41, 570 (1964).

${ }^{3}$ G. M. Begun, W. H. Fletcher, and D. F. Smith, J. Chem.

Phys. 42, 2236 (1965).

${ }^{4}$ H. H. Claassen, E. L. Gasner, H. Y. Kim, and J. L. Huston, J. Chem. Phys. 49, 253 (1968).

${ }^{5}$ L. Helmholz and M. T. Rogers, J. Am. Chem. Soc. 62, 1537
(1940).

${ }^{6}$ D. H. Templeton, A. Zalkin, and J. D. Forrester, J. Am. Chem. Soc. 85, 817 (1963).

${ }^{7}$ H. H. Hyman, in Physical Chemistry: An Advanced Treatise, edited by (H. Eyring, D. Henderson, and W. Jost (Academic, New York, 1970), Vol. 5, pp. 589-662.

${ }^{8}$ S. -C. Hsu, C. - Y Ng, and W. - K. Li, J. Mol. Struct. 16, 125 (1973).

${ }^{9}$ S. W. Peterson, J. H. Holloway, B. A. Coyle, and J. M. Williams, Science 173, 1238 (1971); the preparation of (NO) $\mathrm{XeF}_{8}$ is reported by G. J. Moody and H. Selig, Inorg. Nucl. Chem. Lett. 2, 319 (1966).

${ }^{10} \mathrm{H}$. Selig, Science 144, $537(1964)$.

${ }^{11}$ G. L. Gard and G. H. Cady, Inorg. Chem. 3, 1745 (1964).

${ }^{12}$ K. E. Pullen and G. H. Cady, Inorg. Chem. 5, 2057 (1966); 6, 1300 (1967).

${ }^{13}$ R. D. Peacock, H. Selig, and I. Sheft, Proc. Chem. Soc. $1964,285$.

${ }^{14}$ B. Jaselkis, T. M. Spittler, and J. L. Huston, J. Am. Chem. Soc. 88, 2149 (1966).

${ }^{15}$ H. H. Claassen, G. L. Goodman, and H. Kim, J. Chem. Phys. 56, 5042 (1972).

${ }^{16}$ G. L. Goodman, J. Chem. Phys. 56, 5038 (1972). 